\title{
Adaptation Strategies Followed by Farmers to Combat Impact of Climate Change on Groundwater Irrigation in Least and Highly Vulnerable Districts of Karnataka
}

\author{
Shivakumara, C." and Srikantha Murthy, P.S. \\ ${ }^{1}$ Department of Agricultural Economics, UAS, GKVK, Bengaluru, Karnataka, India \\ *Corresponding author: shivugarje@gmail.com (ORCID ID: 0000-0001-8851-4310 )
}

Received: 24-03-2020

Revised: $17-07-2020$

Accepted: 20-08-2020

\begin{abstract}
Study was conducted in least vulnerable districts (LVD) and highly vulnerable districts (HVD) of Karnataka. The results reveal that, in the LVD most of the farmers perceived that lower productivity and profitability of crops as the most visible impact of the climate change which has been ranked $1^{\text {st }}(75.33$ score) and incidence of farmers suicide with a score of 9.82 being ranked last. In case of HVD, farmers perceived increasing rural-out migration (78.98) as a most threatening impact of climate change hence it is placed at $1^{\text {st }}$ rank and increasing price of food items with garette score of 27.12 placed at last rank. In both HVD and LVD, most of the farmers chosed drip irrigation, availing crop insurance scheme and construction of farm pond as the first line of defence to mitigate effects of climate change. However, the mitigation measures adopted by farmers to overcome the problem of groundwater depletion and climate change was found to be higher in HVD as against LVD.
\end{abstract}

Highlights

(- This paper mainly focuses on farmers perception and adaptation strategies to be followed by the groundwater irrigated farmers in least and highly climate vulnerable districts of Karnataka.

Keywords: Mitigation strategy, vulnerability, perception, cost of adaptation

Agricultural economy in Karnataka is largely influenced by agroclimatic factors, water and other resource endowments of farmers, technology, infrastructure, tradition, social capital as also the market forces of demand and supply. The state has the second largest drought hit area in the country next to Rajasthan. Availability of water resource plays a crucial role in the cropping pattern in the state. Karnataka's annual rainfall is on an average $1151 \mathrm{~mm}$, of which 80 per cent is received during the southwest monsoon, 12 per cent in the post monsoon period, 7 per cent during summer and 1 per cent in rabi season (Krishna Raj and Chandrakanth, 2018) and volume of groundwater available is 485 TMC which forms 22 per cent of the total volume of water which provides irrigation to 50 per cent of the irrigated area, while the other 78 per cent of the total volume of water is surface irrigation, irrigating the remaining 50 per cent of the irrigated area. Groundwater potential of the area depends on rainfall and efforts to recharge. Change in climatic conditions directly affects the hydrological cycle and gradually the groundwater table. Obviously the economic impact of climate change will severely affect the food security as well as livelihood security including health security of farmers. This is the lopsided distribution of surface water compared with groundwater resource for irrigation. Without

How to cite this article: Shivakumara, C. and Srikantha Murthy, P.S. (2020). Adaptation Strategies Followed by Farmers to Combat Impact of Climate Change on Groundwater Irrigation in Least and Highly Vulnerable Districts of Karnataka. Economic Affairs, 65(3): 415-420.

Source of Support: None; Conflict of Interest: None 
loss of generality, it can be inferred that $1 / 4^{\text {th }}$ of total water (given by groundwater) irrigates half the irrigated land while $3 / 4$ ths of total water (given by surface water) irrigates the other half of irrigated area in Karnataka.

Groundwater irrigation is fraught with negative reciprocal externality due to over exploitation, resulting from violation of the isolation distance among wells leading to cumulative interference among irrigation wells affecting the cone of depression. Coping mechanism refers to measures adopted by farmers in the wake of negative reciprocal externality in groundwater irrigation. They can be classified as measures pertaining to markets, technologies and institutions. Market measures reflect the response of farmers to relative market price ratio reflected through choice of crops they cultivate and the extent of area sown in each season. Technologies have demand and supply side. Demand side technologies refer to those which result into efficient use of groundwater resources (adoption of micro-irrigation for instance). Supply side technology refers to those measures which augment the supplies of groundwater (Recharge efforts for instance). Thus, adoption of technologies to meet both the demand and supply side forces in groundwater reflect mitigation strategies of farmers through technology adoption (Kirankumar Patil, 2014).

\section{METHODOLOGY}

\section{Selection and description of the study area}

Karnataka is the second largest drought prone area in the country next only to Rajasthan and water availability is one of the major concerns in the state. The present study was conducted in eight districts of Karnataka state viz. Bidar, Koppal, Kolar, Chitradurga, Davanagere, Shivamogga, Udupi and Dakshina Kannada. The study area was selected based on the composite climate vulnerability index (Table 1).

For easy comparison, districts were classified as least vulnerable and highly vulnerable using below mentioned criteria.

The arithmetic mean $(\bar{X})$ and standard deviation (SD) of composite vulnerability index were calculated in order to demarcate boundaries between least and highly vulnerable districts.

Least vulnerable districts: Mean minus standard deviation $(\overline{\mathrm{X}}-\mathrm{SD})$ of composite vulnerability index to demarcate least vulnerable districts (0.440 to 0.528).

Highly vulnerable districts: Mean plus standard deviation (+SD) of composite vulnerability index to demarcate the highly vulnerable districts $(0.628$ to 0.677$)$.

Table 1: Composite index of vulnerability

\begin{tabular}{llllll}
\hline Sl. No. & Districts & Composite index & S1. No & Districts & Composite index \\
\hline 1 & Bidar & 0.677 & 16 & Chamarajanagar & 0.579 \\
2 & Kolar & 0.658 & 17 & Mysuru & 0.574 \\
3 & Yadgir & 0.638 & 18 & Tumakuru & 0.573 \\
4 & Koppal & 0.636 & 19 & Hassan & 0.571 \\
5 & Raichur & 0.628 & 20 & Bengaluru rural & 0.558 \\
6 & Chitradurga & 0.628 & 21 & Mandya & 0.557 \\
7 & Kalaburagi & 0.625 & 22 & Belagavi & 0.555 \\
8 & Ramanagara & 0.604 & 23 & Ballari & 0.543 \\
9 & Vijayapura & 0.602 & 24 & Bengaluru urban & 0.538 \\
10 & Gadag & 0.599 & 25 & Chikkamagaluru & 0.531 \\
11 & Dharwad & 0.596 & 26 & Uttarakannada & 0.530 \\
12 & Kodagu & 0.594 & 27 & Dakshinakannada & 0.528 \\
13 & Chikballapur & 0.593 & 28 & Udupi & 0.486 \\
14 & Bagalkot & 0.590 & 29 & Davanagere & 0.486 \\
15 & Haveri & 0.580 & 30 & Shivamogga & 0.440 \\
\hline
\end{tabular}

Source: Shivakumara and Murthy, 2019. 


\section{Analytical tools used}

\section{Garrett's Ranking Technique}

To document the perception and problems faced by farmers during the climate change adaptation, Garrett ranking technique was used. The response of farmers on the possible opinion were obtained on rank basis to work out the total score.

Garrett's ranking technique gives the change of orders of opinion into numerical scores. The major advantage of this technique as compared to simple frequency distribution is that, here opinions are arranged based on their importance from the point of view of respondents.

Garrett's formula for converting ranks into per cent is given bellow:

Per cent position $=100\left(R_{i j}-0.5\right) / N_{j}$

Where, $R_{i j}=$ rank given for $i^{\text {th }}$ factor by $j^{\text {th }}$ individual $N_{j}=$ Number of factors ranked by $j^{\text {th }}$ individual

By referring to Garrett's table, the relative position of each rank obtained from the above equation was translated into scores (transmutation of orders of merit into units of amount or scores) for each factor, scores of all individuals were added and then divided by the total number of respondents for the specific factor. Finally, mean scores were arranged in descending order for all the factors and the ranks were given.

\section{RESULTS AND DISCUSSION}

The adaptation process seeks to mitigate climate vulnerability and helps to reap potential benefits by altering activities, practices and systems ranging from short-term to long-term coping. Agricultural and rural communities follow a variety of strategies and activities in response to various threats due to experiential awareness built over the years. Potential climate changes, agro-climatic and socio-economic factors influence the strategies adopted at the farm level, and differ across regions. Adaptation strategies are the ones that are tailored to minimize problems of groundwater depletion. A livelihood system's ability to respond to shocks through coping strategies is a key determinant of rural livelihood resilience and vulnerability.

\section{Farmers perception on climate change and groundwater depletion}

In order to adapt farm-centered mitigation strategies effectively, the awareness of farmers about climate change and its consequences are important. The results presented in Table 2 reveal that, in the LVD most of the farmers perceived that lower productivity and profitability of crops as the most visible impact of the climate change which has been ranked $1^{\text {st }}$ (75.33 score).

Increasing rural-out migration stands at $2^{\text {nd }}$ rank with a score of 71.58 . Food insecurity is perceived as $3^{\text {rd }}$ most important impact of climate change with a score of 64.23 followed by increase in price of food items (50.22) being ranked $4^{\text {th }}$. Increase in incidence of farmers indebtedness with a score of 41.90 stands at $5^{\text {th }}$ rank.

The sixth rank has been given to Nutritional insecurity and health-related problems (30.69) followed by the land mortgage (19.28) which stands at $7^{\text {th }}$ position and lastly, incidence of farmers suicide (9.82) is standing at $8^{\text {th }}$ rank.

In case of HVD, farmers perceived increasing ruralout migration (78.98) as a most threatening impact

Table 2: Farmers perception on Socio-economic impacts of Groundwater depletion and Climate change

\begin{tabular}{|c|c|c|c|c|c|}
\hline \multirow{2}{*}{ Sl. No. } & \multirow{2}{*}{ Particulars } & \multicolumn{2}{|l|}{ LVD } & \multicolumn{2}{|l|}{ HVD } \\
\hline & & Garett Score & Rank & Garett Score & Rank \\
\hline 1 & Lower productivity and profitability of crops & 75.33 & I & 64.55 & II \\
\hline 2 & Food insecurity & 64.23 & III & 37.38 & VI \\
\hline 3 & The increasing price of food items & 50.22 & IV & 27.12 & VIII \\
\hline 4 & Increasing rural-out migration & 71.58 & II & 78.98 & I \\
\hline 5 & Incidence of farmers suicide & 9.82 & VIII & 40.84 & $\mathbf{V}$ \\
\hline 6 & Increase in incidence of farmers indebtedness & 41.90 & $\mathbf{V}$ & 43.32 & IV \\
\hline 7 & Nutritional insecurity and health related problems & 30.69 & VI & 32.09 & VII \\
\hline 8 & Land mortgage & 19.28 & VII & 46.83 & III \\
\hline
\end{tabular}


of climate change hence it is placed at $1^{\text {st }}$ rank. Lower productivity and profitability of crops stood at $2^{\text {nd }}$ rank with a score of 64.55 . Land mortgage (46.83) was positioned at $3^{\text {rd }}$ rank. The fourth rank was given to the statement viz; increase in incidence of farmers indebtedness (43.32). Incidence of farmers suicide (40.84) stood at $5^{\text {th }}$ rank followed by food insecurity (37.38). Nutritional insecurity and health-related problems (32.09) and increasing price of food items (27.12) were ranked $6^{\text {th }}, 7^{\text {th }}$ and $8^{\text {th }}$ correspondingly.

The findings are in agreement with the results of the study conducted by Varsha Kumari (2016) on climate change impact on agriculture and adaptation strategies of farmers. The results showed that 'Decline in groundwater levels ' was perceived as the $1^{\text {st }}$ and most visible impact of climate change followed by 'Change in rainfall patterns', 'water scarcity in surface water bodies' and 'Decrease in soil productivity'. The finding also matches the results of the study undertaken by Udmale et al. (2014) on farmers understanding of the effects of drought, regional adaptation and mitigation measures in Maharashtra State.

\section{Measures undertaken by the farmers to address the problems of groundwater depletion and climate change}

The different adaptation strategies adopted by the sample farmers in LVD were studied and the results are presented in Table 3. The observations depict that 43 respondents among small farmers in the LVD switched to drip irrigation due to adverse effects climate change and ranked it as number one strategy. Nineteen farmers adopted crop insurance as a strategy to tackle the climate change problem and it stands at $2^{\text {nd }}$ rank among the mitigation measures. Diversification to non-farm income activities is ranked as $3^{\text {rd }}$ important measure which has reported by 18 respondents. Among all the small farmers only one respondent adopted SRI method as a strategy to address the climate change problems and hence was assigned $10^{\text {th }}$ rank. However, none of the respondent farmers adopted water harvesting technique as a mitigation strategy.

In the medium farmers category, the majority of the farmers (37) opted the drip irrigation as a mitigation measure to address impact of climate change and assigned it $1^{\text {st }}$ rank. Twenty-five farmers took crop insurance as an adoptive measure and it stood at $2^{\text {nd }}$ rank. Construction of farm ponds was given the $3^{\text {rd }}$ rank as it was adopted by 18 farmers. Three farmers were following groundwater recharging and it was placed at $9^{\text {th }}$ rank. Two farmers chose alternate cropping choice as a measure and was ranked $10^{\text {th }}$. Only one farmer switched to the SRI method which was ranked $11^{\text {th }}$.

Most of the large farmers (20) chose crop insurance scheme as number one measure to mitigate the effect of climate change. Drip irrigation was given the $2^{\text {nd }}$ rank as it was adopted by 15 farmers.

Table 3: Measures undertaken by the farmers to address the problem of groundwater depletion and climate change in LVD

\begin{tabular}{|c|c|c|c|c|c|c|c|}
\hline \multirow{3}{*}{ S1. No. } & \multirow{3}{*}{ Particulars } & \multicolumn{6}{|c|}{ Number of respondents } \\
\hline & & \multicolumn{2}{|c|}{ Small farmers (54) } & \multicolumn{2}{|c|}{ Medium farmers (42) } & \multicolumn{2}{|c|}{ Large farmers (24) } \\
\hline & & Frequency & Rank & Frequency & Rank & Frequency & Rank \\
\hline 1 & Groundwater recharge & - & & 3 & IX & 3 & $\mathrm{X}$ \\
\hline 2 & Drip irrigation & 43 & $\mathrm{I}$ & 37 & I & 15 & II \\
\hline 3 & Sprinkler irrigation & 16 & IV & 12 & $\mathrm{~V}$ & 10 & $\mathrm{~V}$ \\
\hline 4 & Change in crop choice & 2 & IX & 2 & $x$ & 4 & IX \\
\hline 5 & Use of SRI method(in case of paddy crop) & 1 & $x$ & 1 & XI & 1 & XII \\
\hline 6 & Construction of farm pond & 15 & $\mathrm{~V}$ & 18 & III & 14 & III \\
\hline 7 & Adoption of drought resistant varieties & 3 & VIII & 6 & VII & 12 & IV \\
\hline 8 & Changing the time of agricultural operations & 12 & VI & 8 & VI & 9 & VI \\
\hline 9 & In-situ moisture conservation & 5 & VII & 13 & IV & 8 & VII \\
\hline 10 & Diversification to non-farm income activities & 18 & III & 4 & VIII & 5 & VIII \\
\hline 11 & Use of rain water harvesting technique & - & - & - & - & 2 & XI \\
\hline 12 & Availing crop insurance services & 19 & II & 25 & II & 20 & I \\
\hline
\end{tabular}


Table 4: Measures undertaken by the farmers to address the problem of groundwater depletion and climate change in HVD

\begin{tabular}{llllllll}
\hline \multirow{2}{*}{ S1. No } & \multirow{2}{*}{ Particulars } & \multicolumn{2}{c}{ Number of respondents } \\
\cline { 3 - 7 } & & \multicolumn{2}{c}{ Small farmers (47) } & Medium farmers (51) & \multicolumn{2}{c}{ Large farmers (22) } \\
\cline { 3 - 8 } & & Frequency & Rank & Frequency & Rank & Frequency & Rank \\
\hline 1 & Groundwater recharge & 0 & - & 2 & XI & 4 & X \\
2 & Drip irrigation & 47 & I & 51 & I & 22 & I \\
3 & Sprinkler irrigation & 11 & V & 16 & V & 14 & IV \\
4 & Change in crop choice & 7 & VI & 9 & VI & 5 & IX \\
5 & Construction of farm pond & 24 & IV & 32 & III & 18 & II \\
6 & Adoption of drought resistant varieties & - & & 3 & X & 6 & VIII \\
7 & Changing time of agricultural operations & 6 & VII & 5 & IX & 11 & V \\
8 & In-situ moisture conservation & 3 & VIII & 7 & VII & 9 & VI \\
9 & Diversification to non-farm income activities & 26 & III & 19 & IV & 8 & VII \\
10 & Use of rain water harvesting technique & 0 & - & 4 & VIII & 3 & XI \\
11 & Availing crop insurance services & 30 & II & 35 & II & 17 & III \\
\hline
\end{tabular}

Fourteen farmers adopted the construction of farm pond as a measure of climate change and it was given the $3^{\text {rd }}$ rank. Groundwater recharging was adopted by three farmers and it stood at $10^{\text {th }}$ rank. Use of rainwater harvesting was adopted by only two farmers and ranked it $11^{\text {th }}$. Only one farmer adopted SRI method as a strategy to address the problem of climate change which stood at $12^{\text {th }}$ rank.

Table 4 shows the measures undertaken by the farmers from the HVD. Majority of the small farmers (47) adopted drip irrigation as a strategy to address the problem of climate change and was assigned $1^{\text {st }}$ rank. Thirty farmers availed crop insurance scheme to cope up with the climate change effects and it stood at $2^{\text {nd }}$ rank.

Switching over to the non-farm income activity like dairy, is also one another way to manage climate change as adopted by the farmers (26) this measure stands at 3rd rank. Twenty four farmers opined that construction farm pond was a measure to mitigate the climate change problem and ranked was at 4th. Only three farmers have adopted the strategy of in-situ moisture conservation which is given the 8th rank. None of the small farmers indicated the strategies like groundwater recharge, adoption of drought-resistant varieties and rainwater harvesting. In the category of medium farmers, most of the farmers (51) accepted drip irrigation as a measure to the climate change hence it was given the $1^{\text {st }}$ rank. Availing the crop insurance scheme as the strategy was given $2^{\text {nd }}$ rank as it was adopted by 35 farmers.
The third rank has been given to the construction of farm pond as agreed by 32 farmers. Three farmers chose the strategy of adoption of drought-resistant varieties to overcome the effect of climate change and it is ranked at $10^{\text {th }}$ place. Only two farmers opined that groundwater recharge is one of the solutions to overcome climate change effects and hence it is ranked $11^{\text {th }}$.

In the category of large farmers also the majority of the farmers (22) opted drip irrigation as a choice to mitigate climate change vulnerability hence it stands at $1^{\text {st }}$ rank. Construction of farm pond has been given $2^{\text {nd }}$ rank as it was adopted by 18 farmers. Seventeen farmers opted crop insurance as a measure to overcome climate change and it given $3^{\text {rd }}$ rank. Measures like groundwater recharge and use of rainwater harvesting stood at $10^{\text {th }}$ and $11^{\text {th }}$ rank respectively.

In both HVD and LVD, most of the farmers were chose drip irrigation, availing crop insurance scheme and construction of farm pond as the first line of defence to mitigate effects of climate change. However, the mitigation measures adopted by farmers to overcome the problem of groundwater depletion and climate change was found to be higher in HVD as against LVD. Thus, the hypothesis has been accepted.

The findings related to mitigation measures adopted by the farmers in the LVD in light of climate change are presented in Table 5. Amongst different mitigation measures the cost incurred 
Table 5: The mitigation measures adopted by the farmers and its associated cost in LVD (₹/farm)

\begin{tabular}{llll}
\hline Particulars & Small farmers & Medium farmers & Large farmers \\
\hline Drip irrigation & 33330 & 42492 & 73564 \\
Sprinkler irrigation & 30972 & 34780 & 54680 \\
Groundwater recharging structure & 35600 & 36840 & 40500 \\
Construction of farm ponds & $38650^{*}$ & $48034^{* *}$ & $69378^{* * *}$ \\
In-situ moisture conservation & 12560 & 13450 & 24600 \\
Crop insurance premium & 675 & 987 & 1890 \\
\hline
\end{tabular}

Note: Dimensions of farm pond $(l \times b \times h$ in $m$ trs $): * 10 \times 10 \times 3,{ }^{* *} 15 \times 15 \times 3,{ }^{* * *} 18 \times 18 \times 3$ and $21 \times 21 \times 3$.

for construction of farm ponds was highest with $₹ 38650$ and ₹ 48034 in small and medium farmers, respectively. In the large farmers category, drip irrigation accounted for the highest cost with ₹ 73564. Among all the farmers, cost incurred by small farmers on recharging groundwater and rain water harvesting was highest next to construction of farm ponds compared medium and large farmers. Furthermore, small farmers incur $₹ 12560$ on in-situ moisture conservation in wake of climate change. The large farmers incur ₹ 24600 on in situ moisture conservation mainly due to large scale cultivation of plantation crops (Coconut and Arecanut) in the study area.

Table 6: Summary of cost incurred on mitigation measures adopted by the farmers of HVD (₹/farm)

\begin{tabular}{|c|c|c|c|}
\hline Particulars & $\begin{array}{l}\text { Small } \\
\text { farmers }\end{array}$ & $\begin{array}{l}\text { Medium } \\
\text { farmers }\end{array}$ & $\begin{array}{l}\text { Large } \\
\text { farmers }\end{array}$ \\
\hline Drip irrigation & 58470 & 78390 & 96545 \\
\hline Sprinkler irrigation & 58333 & 64352 & 74360 \\
\hline $\begin{array}{l}\text { Ground water recharge } \\
\text { structure \& Rain water } \\
\text { harvesting }\end{array}$ & 42560 & 42800 & 46380 \\
\hline $\begin{array}{l}\text { Construction of farm } \\
\text { pond }\end{array}$ & $43342^{*}$ & $92087^{* *}$ & $124348^{* * *}$ \\
\hline $\begin{array}{l}\text { In-situ moisture } \\
\text { conservation }\end{array}$ & 16840 & 18956 & 18645 \\
\hline Availing crop insurance & 786 & 875 & 2800 \\
\hline
\end{tabular}

Note: Dimensions of farm pond $(l \times b \times h$ in mtrs):* $10 \times 10 \times 3$, ** $15 \times 15 \times 3,{ }^{* * *} 18 \times 18 \times 3$ and $21 \times 21 \times 3$.

Cost incurred on mitigation measures adopted by the farmers of HVD were given in Table 6 and result revealed that, among different mitigation measures for construction of farm ponds was highest with ₹ 43342, ₹ 92087 and ₹ 124348 in small, medium and large farmers, respectively. Among all the farmers, cost incurred by farmers on drip irrigation was highest followed by sprinkler irrigation, construction of groundwater recharge structure, in-situ moisture conservation and availing crop insurance.

\section{CONCLUSION}

In both HVD and LVD, most of the farmers chose drip irrigation, availing crop insurance scheme and construction of farm pond as the first line of defence to mitigate effects of climate change. However, the mitigation measures adopted by farmers to overcome the problem of groundwater depletion and climate change was found to be higher in HVD as against LVD.

\section{ACKNOWLEDGMENTS}

Authors acknowledge faculty of Agricultural Economics, UAS(B) for their valuable suggestions during preparation of this article.

\section{REFERENCES}

Krishna Raj and Chandrakantha, M.G. 2018. Water Resources and Irrigation Management, State of Environment Report for Karnataka, Institute for Social and Economic Change, Bengaluru.

Kiran Kumar, R.P. 2014. Economics of coping mechanism in ground water irrigation role of markets, technologies and institution. Ph.D. Thesis (Unpub.), Univ. of Agril. Sci., Bengaluru.

Shivakumara, C. and Srikantha Murthy, P.S. 2019. Mapping a Climate Change Vulnerability Index: An Assessment in Agricultural, Geological and Demographic Sectors across the Districts of Karnataka (India), International Journal of Environment and Climate Change, 9(8): 447-456.

Udmale, P., Ichikawa, Y., Manandhar, S., Ishidaira, H. and Kiem, A.S. 2014. Farmer's Perception of Drought Impacts, Local Adaptation and Administrative Mitigation Measures in Maharashtra State, India. International Journal of Disaster Risk Reduction, 10: 250-69.

Varshakumari, 2016. Climate change impact on agriculture and adaptation strategies of farmers, M.Sc. Thesis (Unpub.), Banaras Hindu University, Varanasi. 